\title{
Hypnotic Activities of Chamomile and Passiflora Extracts in Sleep-Disturbed Rats
}

\author{
Kazuaki Shinomiya, ${ }^{a}$ Toshio Inoue, ${ }^{b}$ Yoshiaki Utsu, ${ }^{a}$ Shin Tokunaga, ${ }^{a}$ Takayoshi Masuoka, ${ }^{a}$ \\ Asae OHMORI, ${ }^{a}$ and Chiaki KameI, ${ }^{*, a}$ \\ ${ }^{a}$ Department of Pharmacology, Faculty of Pharmaceutical Sciences, Okayama University; 1-1-1 Tsushima-naka, \\ Okayama 700-8530, Japan: and ${ }^{b}$ Material R\&D Laboratory, Ogawa \& Co., Ltd.; 15-7 Chidori, Urayasu, Chiba \\ 279-0032, Japan. Received November 19, 2004; accepted February 1, 2005
}

In the present study, we investigated hypnotic activities of chamomile and passiflora extracts using sleep-disturbed model rats. A significant decrease in sleep latency was observed with chamomile extract at a dose of $300 \mathrm{mg} / \mathrm{kg}$, while passiflora extract showed no effects on sleep latency even at a dose of $3000 \mathrm{mg} / \mathrm{kg}$. No significant effects were observed with both herbal extracts on total times of wakefulness, non-rapid eye movement (nonREM) sleep and REM sleep. Flumazenil, a benzodiazepine receptor antagonist, at a dose of $3 \mathrm{mg} / \mathrm{kg}$ showed a significant antagonistic effect on the shortening in sleep latency induced by chamomile extract. No significant effects were observed with chamomile and passiflora extracts on delta activity during non-REM sleep. In conclusion, chamomile extract is a herb having benzodiazepine-like hypnotic activity.

Key words chamomile; passiflora; insomnia; herbal drug; sleep-disturbed model; rat

Benzodiazepines and benzodiazepine analogues are the most widely used hypnotic drugs since the 1960 s. ${ }^{1)}$ However, it is well known that benzodiazepines have many untoward reactions, such as drug dependence, tolerance, rebound insomnia, amnesia and muscle relaxation. ${ }^{2,3)}$ Therefore, it seems likely that these hypnotics need to be used cautiously.

On the other hand, herbal drugs, such as chamomile and passiflora, are extensively used as traditional medicine for treatment of insomnia and anxiety. There have been some reports on the hypnotic effects of these herbal extracts in humans. ${ }^{4,5)}$ In animal experiments, Soulimani et al. ${ }^{6}$ also reported that the aqueous extract of passiflora incarnata $L$ caused a decrease of rearing and locomotion in the staircase apparatus or exploratory test. The aqueous extract of passiflora also induced sleep after treatment with a subpharmacological dose of pentobarbital in mice. ${ }^{6)}$ Della Loggia et al. ${ }^{7)}$ demonstrated that the extracts from Matricaria chamomilla and Passiflora incarnata showed a significant increase in barbiturates-induced sleep time in mice. However, the literature dealing with the hypnotic activities of chamomile and passiflora extracts by measuring electroencephalogram (EEG) and electromyogram (EMG) in animals is scanty. The normal animals have high-baseline sleep time, and the hypnotic potencies of chamomile and passiflora may be mild compared with those of benzodiazepines and benzodiazepine analogues. Therefore, it may be difficult to evaluate the hypnotic activities of the herbal drugs in normal animals.

In the previous study, we developed a sleep-disturbed model that is useful for evaluating hypnotic activities by placing rats on a grid in a cage filled with water to $1 \mathrm{~cm}$ below the grid surface. ${ }^{8)}$ The hypnotic effects of drugs in rats placed on the grid suspended over water were more potent than that in rats placed on sawdust. ${ }^{8,9)}$ In the present study, we studied the hypnotic activities of chamomile and passiflora extracts using the sleep-disturbed model rats.

\section{MATERIALS AND METHODS}

Animals Thirty-two male Wistar rats weighing 220
$300 \mathrm{~g}$ (Japan SLC, Shizuoka, Japan) were used. All animals were maintained in an air-conditioned room with controlled temperature $\left(24 \pm 2{ }^{\circ} \mathrm{C}\right)$ and humidity $(55 \pm 15 \%)$. They were housed in aluminium cages with sawdust and kept under a light-dark cycle (lights on from 7:00 to 19:00). The animals were allowed free access to food and water except during the experiments. All procedures involving animals were conducted in accordance with the guidelines of the Animal Care and Use Committee, Faculty of Pharmaceutical Sciences, Okayama University.

Surgery The animals were anesthetized with pentobarbital sodium $\left(\mathrm{Nembutal}^{\mathbb{Q}}, 35 \mathrm{mg} / \mathrm{kg}\right.$, i.p., Abbott Laboratories, North Chicago, IL, U.S.A.), then fixed in a stereotaxic apparatus (SR-5, Narishige, Tokyo, Japan). For electroencephalogram (EEG) recording, a stainless steel screw electrode was chronically implanted into the right frontal cortex (A: 0.5, L: 3.0) according to the atlas of Paxinos and Watson. ${ }^{10}$ ) To record the electromyogram (EMG), stainless steel wire electrodes $(200 \mu \mathrm{m})$ were implanted into the dorsal neck muscle. A stainless steel screw fixed in the left frontal bone served as a reference electrode. The electrodes were connected to a miniature receptacle and the whole assembly was fixed to the skull with dental cement. At least $7 \mathrm{~d}$ were allowed for recovery from the surgery.

EEG and EMG Recordings EEG and EMG were recorded with an electroencephalograph (Model EEG 5113, Nihon Kohden, Tokyo, Japan) from 9:00 to 15:00. The recording was carried out according to the method described previously. ${ }^{9,11,12)}$ The signals were amplified and filtered (EEG, $0.5-30 \mathrm{~Hz}$; EMG, 16-128 Hz), then digitized at a sampling rate of $128 \mathrm{~Hz}$ and recorded using the data acquisition program SleepSign ver. 2.0 (Kissei Comtec, Nagano, Japan). EEG and EMG of the rat were measured in a cylindrical plastic cage. A grid floor was placed inside the plastic cage. The cage was filled with water up to $1 \mathrm{~cm}$ below the grid surface. The stainless steel rods of the grid ( $3 \mathrm{~mm}$ wide) were set $2 \mathrm{~cm}$ apart from each other. The observation cage was placed in a sound-proof and electrically-shielded box.

Sleep-Wake State Analysis The sleep-wake states were 
automatically classified in 10-s epochs as wake, non-rapid eye movement (non-REM) or REM sleep by SleepSign ver. 2.0 according to the criteria previously described. ${ }^{8,13)}$ As a final step, defined sleep-wake stages were examined visually, and corrected, if necessary. Each state was characterized as follows: wake, low-amplitude EEG and high-voltage EMG activities; non-REM sleep, high-amplitude slow or spindle EEG and low-EMG activities; REM sleep, low-voltage EEG and EMG activities.

Calculation for Delta Activity during Non-REM Sleep The delta activity within non-REM sleep was determined using a program of SleepSign ver. 2.0. The power spectrum densities, integrated and averaged, could be divided into the 4 frequency areas: delta wave $(0.5-4 \mathrm{~Hz})$, theta wave (4$8 \mathrm{~Hz})$, alpha wave $(8-13 \mathrm{~Hz})$ and beta wave $(13-30 \mathrm{~Hz})$. The data of delta power in non-REM sleep were expressed as a percentage of the average delta activity during non-REM sleep during the entire recording period of each control group. $^{14,15)}$

Drugs The following drugs were used: chamomile extract (Ogawa \& Co., Ltd., Chiba, Japan), passiflora extract (Ogawa \& Co., Ltd.) and flumazenil (Sigma, St. Louis, MO, U.S.A.). The chamomile and passiflora were extracted by refluxing in water for $1 \mathrm{~h}$ from the flower part of Matricaria chamomilla or the aerial part of Passiflora incarnata, respectively. The chamomile and passiflora extract were suspended in $0.5 \%$ carboxymethyl cellulose (CMC) solution and administered orally at 9:00, and EEG and EMG were measured for $6 \mathrm{~h}$ after drug administration. In the antagonism experiments, flumazenil was dissolved in $10 \%$ dimethyl sulfoxide and injected intraperitoneally before the drug tests. Eight rats were used in each group, and counterbalanced design for drug dosage was used. Drugs were administered at intervals of $7 \mathrm{~d}$ when the same rats were used for repeated experiments. Each rat was subjected to experiment for drug study three or four times.

Data Analysis and Statistics Values shown are means \pm S.E.M. One-way analysis of variance (ANOVA) with the Dunnett's test was used for estimating the drug effects. Sleep latency was defined as the time from drug administration up to the first 12 consecutive 10 -s epochs of sleep.

\section{RESULTS}

Effects of Herbal Extracts on Sleep Parameters A significant shortening of sleep latency was observed with chamomile extract at a dose of $300 \mathrm{mg} / \mathrm{kg}$. On the other hand, passiflora extract had no effects on sleep latency even at a dose of $3000 \mathrm{mg} / \mathrm{kg}$ (Fig. 1). No significant effects were observed with both herbal extracts on total times of wakefulness, non-REM sleep or REM sleep (Fig. 2).

Effect of Flumazenil on the Shortening in Sleep Latency Induced by Chamomile Extract Flumazenil alone showed no significant effects on sleep latency at doses of 1 and $3 \mathrm{mg} / \mathrm{kg}$. The shortening of sleep latency caused by chamomile extract $(300 \mathrm{mg} / \mathrm{kg}$ ) was significantly antagonized by flumazenil at a dose of $3 \mathrm{mg} / \mathrm{kg}$ (Fig. 3).

Effects of Herbal Extracts on Delta Activity during Non-REM Sleep No significant effects were observed with chamomile and passiflora extracts on delta power during non-REM sleep (Table 1).

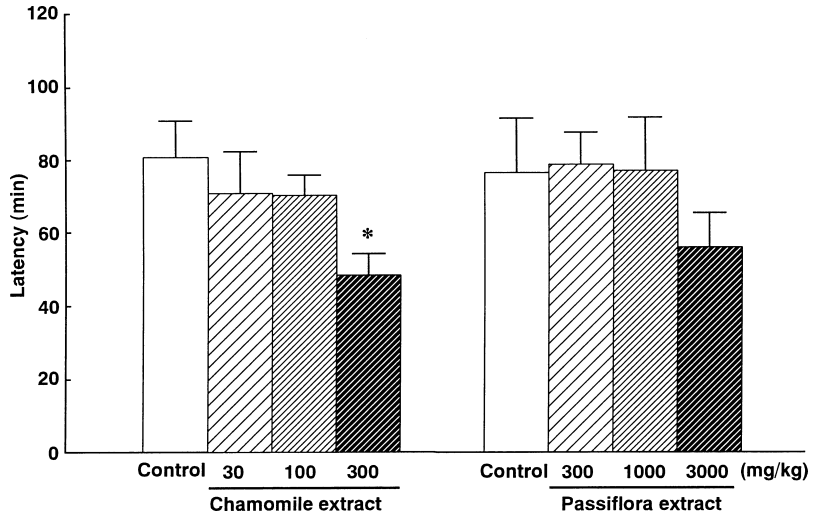

Fig. 1. Effects of Herbal Extracts on Sleep Latency in Sleep-Disturbed Rats

Columns and vertical bars represent means \pm S.E.M. $(n=8)$. Drugs were administered orally. $*$ Significantly different from control group at $p<0.05$

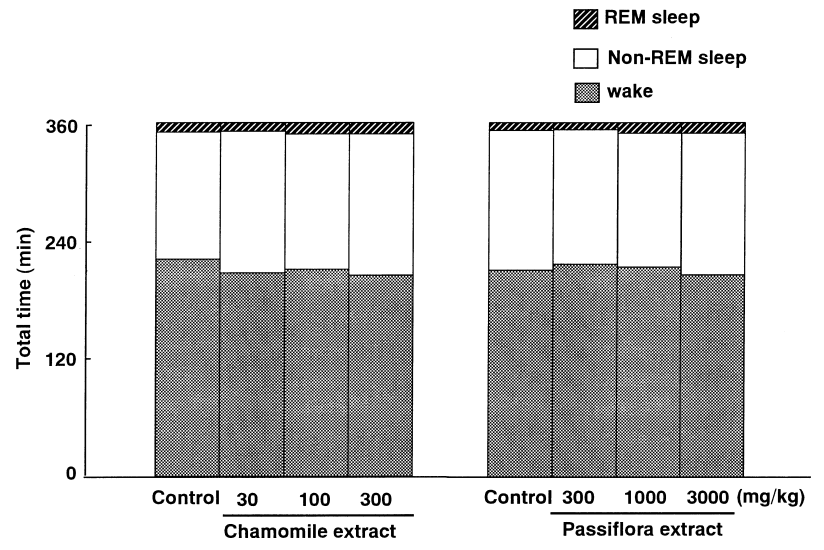

Fig. 2. Effects of Herbal Extracts on Total Time of Each Sleep State in Sleep-Disturbed Rats

Columns represent the means of each sleep state $(n=8)$. Drugs were administered orally, and EEG and EMG were measured for $6 \mathrm{~h}$.

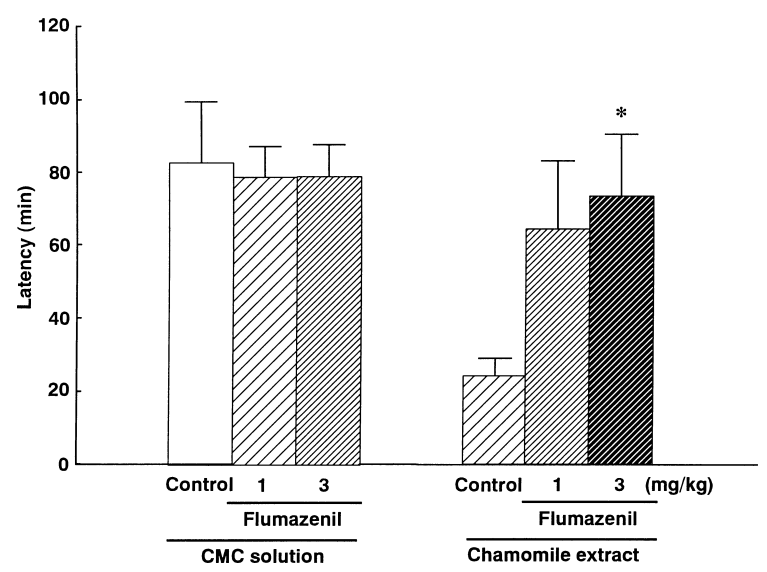

Fig. 3. Effects of Flumazenil on the Shortening in Sleep Latency Induced by Chamomile Extract in Sleep-Disturbed Rats

Columns and vertical bars represent means \pm S.E.M. $(n=8)$. Chamomile extract was administered orally, and flumazenil was injected intraperitoneally. $*$ Significantly different from control group at $p<0.05$. 
Table 1. Effects of Herbal Extracts on Delta Activity During Non-REM Sleep in Sleep-Disturbed Rats

\begin{tabular}{|c|c|c|c|c|c|c|}
\hline \multirow{2}{*}{ Dose (mg/kg, p.o.) } & \multicolumn{6}{|c|}{ EEG activity (\%) } \\
\hline & $0-1$ & $1-2$ & $2-3$ & $3-4$ & $4-5$ & $5-6(h)$ \\
\hline \multicolumn{7}{|l|}{ Chamomile extract } \\
\hline Control & $67.2 \pm 5.4$ & $86.8 \pm 7.4$ & $96.4 \pm 9.4$ & $104.9 \pm 8.6$ & $108.9 \pm 7.5$ & $104.9 \pm 8.2$ \\
\hline 30 & $73.8 \pm 11.4$ & $101.2 \pm 15.8$ & $106.9 \pm 12.0$ & $116.8 \pm 13.6$ & $113.2 \pm 13.3$ & $93.2 \pm 10.5$ \\
\hline 100 & $87.0 \pm 8.9$ & $95.2 \pm 8.0$ & $107.5 \pm 11.1$ & $111.8 \pm 15.4$ & $110.8 \pm 10.1$ & $99.8 \pm 10.3$ \\
\hline 300 & $84.0 \pm 6.9$ & $97.8 \pm 7.8$ & $112.2 \pm 8.1$ & $108.3 \pm 8.6$ & $113.7 \pm 19.1$ & $102.7 \pm 16.3$ \\
\hline \multicolumn{7}{|l|}{ Passiflora extract } \\
\hline Control & $69.3 \pm 5.4$ & $94.5 \pm 5.2$ & $105.5 \pm 4.4$ & $108.6 \pm 5.1$ & $100.6 \pm 3.2$ & $98.2 \pm 3.9$ \\
\hline 300 & $67.6 \pm 5.5$ & $83.4 \pm 6.4$ & $97.2 \pm 5.1$ & $103.1 \pm 4.8$ & $109.4 \pm 9.1$ & $100.4 \pm 5.0$ \\
\hline 1000 & $83.9 \pm 16.1$ & $80.8 \pm 9.1$ & $92.0 \pm 9.8$ & $108.7 \pm 7.8$ & $104.2 \pm 5.0$ & $97.2 \pm 6.5$ \\
\hline 3000 & $72.7 \pm 7.0$ & $88.6 \pm 6.6$ & $107.1 \pm 10.6$ & $94.8 \pm 6.8$ & $97.6 \pm 5.5$ & $87.9 \pm 7.1$ \\
\hline
\end{tabular}

Data represent means \pm S.E.M. $(n=8)$. Drugs were administered orally.

\section{DISCUSSION}

The present study was undertaken to investigate the hypnotic activities of chamomile and passiflora extracts using the sleep-disturbed model rats. As shown in the text, chamomile extract at a dose of $300 \mathrm{mg} / \mathrm{kg}$ caused a significant shortening in sleep latency. Gould et al. ${ }^{16)}$ reported that hospitalized patients were given a strong chamomile tea, and ten of the twelve patients immediately fell into a deep sleep lasting $90 \mathrm{~min}$. Della Loggia et $\mathrm{al}^{7)}$ also demonstrated that chamomile extract caused a significant prolongation of sleeping time induced by barbiturates in mice. In addition, Avallone et al. ${ }^{17)}$ showed that apigenin, a flavonoid isolated from Matricaria chamomilla, significantly reduced the locomotor activity in the open field test of rats. These findings strongly suggest that chamomile is a herbal product having hypnotic activity in animals.

To investigate the detailed mechanisms involved in the hypnotic potencies caused by chamomile extract, the effect of flumazenil (benzodiazepine antagonist) on chamomile extract, that it induced the shortening of sleep latency, was studied. Flumazenil at a dose that caused no obvious effect when used alone showed a significant antagonistic effect on the decrease in sleep latency induced by chamomile extract. Viola et al. ${ }^{18)}$ reported that apigenin extracted from chamomile flowers inhibited $\left[{ }^{3} \mathrm{H}\right]$-flunitrazepam binding in the bovine cerebral cortex. Avallone et al. ${ }^{19)}$ also demonstrated that the fractions of extracts from Matricaria chamomilla selectively bound to central benzodiazepine receptors using a $\left[{ }^{3} \mathrm{H}\right]$-flunitrazepam binding assay in rats. On the other hand, it is well known that benzodiazepine receptor agonists cause hypnotic effects on the sleep-wake cycle in humans and animals. ${ }^{8,9,20,21)}$ We have also reported that benzodiazepines, such as triazolam and flunitrazepam caused the decrease in sleep latency, total waking time and delta activity using the present model..$^{8,9,14)}$ From these findings, it seems likely that the shortening of sleep latency induced by chamomile extract may be caused by apigenin, a component of Matricaria chamomilla, through benzodiazepine receptors.

In the previous study using the sleep-disturbed model rats, drugs having the powerful anxiolytic potencies caused more potent hypnotic potencies than those with weak anxiolytic activities. ${ }^{8)}$ Viola et al. ${ }^{18)}$ reported that apigenin induced anxiolytic action in an elevated plus-maze test of mice. From these results, we assume that the effect of chamomile extract may be due to not only hypnotic activities but also anxiolytic activities of the herb.

In conclusion, chamomile extract is a herb having benzodiazepine-like hypnotic activity.

\section{REFERENCES}

1) Parrino L., Terzano M. G., Psychopharmacology, 126, 1-16 (1996)

2) Freeman H. L., J. Drug. Dev. Clin. Pract., 7, 289-302 (1996).

3) Ashton H., Drugs, 48, 25-40 (1994).

4) Carlini E. A., Pharmacol. Biochem. Behav., 75, 501-512 (2003).

5) Gyllenhaal C., Merritt S. L., Peterson S. D., Block K. I., Gochenour T., Sleep Med. Rev., 4, 229-251 (1999).

6) Soulimani R., Younos C., Jarmouni S., Bousta D., Misslin R., Mortier F., J. Ethnopharmacol., 57, 11-20 (1997).

7) Della Loggia R., Tubaro A., Redaelli C., Riv. Neurol., 51, 297-310 (1981).

8) Shinomiya K., Shigemoto Y., Okuma C., Mio M., Kamei C., Eur. J. Pharmacol., 460, 139-144 (2003).

9) Shinomiya K., Shigemoto Y., Omichi J., Utsu Y., Mio M., Kamei C., Psychopharmacology, 173, 203-209 (2004).

10) Paxinos G., Watson C., "The Rat Brain in Stereotaxic Coordinate," 2nd ed., Academic Press, San Diego, 1986.

11) Shinomiya K., Omichi J., Ohnishi R., Ito H., Yoshida T., Kamei C., Eur. J. Pharmacol., 504, 185-189 (2004).

12) Huang Z.-L., Qu W.-M., Li W.-D., Mochizuki T., Eguchi N., Watanabe T., Urade Y., Hayaishi O., Proc. Natl. Acad. Sci., 98, 9965-9970 (2001).

13) Shigemoto Y., Shinomiya K., Mio M., Azuma N., Kamei C., Eur. J. Pharmacol., 494, 161-165 (2004).

14) Shinomiya K., Inoue T., Utsu Y., Tokunaga S., Masuoka T., Ohmori A., Kamei C., Psychopharmacology, (in press).

15) Shinomiya K., Fujimura K., Kim Y., Kamei C., Acta Med. Okayama, (in press).

16) Gould L., Reddy C. V. R., Gomprecht R. F., J. Clin. Pharmacol., 13, 475-479 (1973)

17) Avallone R., Zanoli P., Puia G., Kleinschnitz M., Schreier P., Baraldi M., Biochem. Pharmacol., 59, 1387-1394 (2000).

18) Viola H., Wasowski G., Levi de Stein M., Wolfman C., Silveira R., Dajas F., Medina J. H., Paladini A. C., Planta Med., 61, 213-216 (1995).

19) Avallone R., Zanoli P., Corsi L., Cannazza G., Baraldi M., Phytother Res., 10, S177-S179 (1996).

20) Declerck A. C., Ruwe F., O’Hanlon J. F., Wauquier A., Psychopharmacology, 106, 497-501 (1992).

21) Vogel G. W., Barker K., Gibbons P., Thurmond A., Psychopharmacology, 47, 81-86 (1976). 